\title{
The screening of Duchenne muscular dystrophy patients for submicroscopic deletions
}

\author{
KEVIN HART*, CHARLOTTE COLE*, ALISON WALKER*, \\ SHIRLEY HODGSON*, LYNN JOHNSON*, VICTOR DUBOWITZ†, \\ PETER RAY $\ddagger$, RONALD WORTON, $\ddagger$ AND MARTIN BOBROW* \\ From * the Paediatric Research Unit, United Medical and Dental Schools of Guy's and St Thomas's Hospitals, \\ Guy's Tower, London SE1 9RT; †Department of Paediatrics and Neonatal Medicine, Hammersmith \\ Hospital, London. W12 OHS; and $¥$ Department of Genetics and Research Institute, Hospital for Sick \\ Children, Toronto, Ontario M5G 1 X8, Canada.
}

SUMmARY We have probed the DNA of 156 Duchenne muscular dystrophy (DMD) patients, representing 140 kindreds, with cloned DNA sequences derived from Xp21 and known to show deletions in some DMD patients. Sixteen cases showed a deletion, as defined by lack of hybridisation to one or more of the four probes used. However, two of these cases were brothers, so 15 independent deletions $(10.7 \%)$ are represented. The deletion map is compatible with the suggested order for the sites of the probes used in the study, that is, telomere $\rightarrow$ pERT87·15 $\rightarrow$ pERT87.8 $\rightarrow$ pERT87 $\cdot 1 \rightarrow$ pXJ1 $1 \rightarrow 754 \rightarrow$ centromere. ${ }^{1}$ Further mapping of these deletions and characterisation of the deletion breakpoints should facilitate more accurate molecular localisation of the gene or genes which, when mutated, are responsible for causing DMD.

Duchenne muscular dystrophy (DMD) is an $\mathrm{X}$ linked recessive muscular disorder which affects about 1 in 3000 newborn males, making it the most common of the neuromuscular disorders. A similar, but milder, disorder, Becker muscular dystrophy (BMD), is also known. Despite extensive studies at the protein level, little is known about the biochemical defect in these conditions, or even in which tissues the defect is manifested. ${ }^{2}$ Hence no candidate proteins have been identified to facilitate the elucidation of the defect at the molecular level.

Another approach has been to study cytogenetic aberrations seen in occasional and unusual patients, in an attempt to identify the region of the $X$ chromosome involved in these diseases. Ultimately this could allow the cloning of the gene or genes involved using recombinant DNA techniques, followed by the identification of a protein or proteins involved in DMD. Further study of these putative proteins should allow a fuller understanding of the disease and, hopefully, may allow the development of regimens for alleviation of the symptoms of DMD.

At present, two regions of DNA have been isolated using cytogenetic starting points. The

Received for publication 10 July 1986.

Accepted for publication 4 August 1986.
pERT87 probes $^{3}$ have been derived from a patient with a cytological deletion around $\mathrm{Xp} 21$, who suffered from chronic granulomatous disease, retinitis pigmentosa, and DMD, and had McLeod's phenotype. ${ }^{4}$ These probes are from within the deleted DNA and define the locus designated DXS164. The other region has been derived from the DNA of a female patient who has BMD-like symptoms and carries a balanced translocation, $t(X ; 21)(\mathrm{p} 21 ; \mathrm{p} 12) .{ }^{5}$ Cloning of the breakpoint on the translocated $\mathrm{X}$ chromosome allowed the identification of sequences implicated in the causation of muscular dystrophy. ${ }^{6}$ Unique sequences subcloned from this region form the $\mathrm{XJ}$ series of probes; the locus they define has not yet been designated.

All of the probes developed from the above strategies have been shown to reveal DNA deletions, as defined by lack of hybridisation to restriction enzyme digested Southern blotted DNA. ${ }^{7}$ As DNA deletions of this type have not yet been reported in any normal males, deletion in the vicinity of the loci defined by these probes is presumably the primary cause of the disease in these cases.

In this paper we describe the screening of the DNA of 156 DMD patients, representing 140 mutational events, with probes which reveal dele- 
tions in a proportion of affected males. The four probes used were pERT87.1, pERT87.8, pERT $87 \cdot 15,{ }^{3}$ and $\mathrm{pXJ} 1 \cdot 1 .^{6}$ The patients all fulfilled the classical diagnostic criteria for DMD. However, many were still young and the age at which ambulation will cease cannot be judged. Ambulation after the age of 16 is regarded as an arbitrary distinction between DMD and BMD.

\section{Methods}

DNA was isolated from whole blood leucocytes anticoagulated in EDTA as previously described. ${ }^{8}$ DNA 5 or $10 \mu \mathrm{g}$ was digested with the appropriate restriction enzyme before separation by electrophoresis on horizontal $0 \cdot 8 \%$ agarose gels. The DNA was then transferred to Zetaprobe filters by Southern blotting. ${ }^{7}$ For routine deletion screening, Pst I digested DNA was used.

Cloned specific probe sequences were recovered from low melting point agarose and were routinely labelled with 32P-dCTP to a high specific activity, using a hexanucleotide primed reaction. ${ }^{9}$ Unincorporated nucleotides were removed by separation in G50 columns.

Probe $754^{10}$ was used in all cases as a control, to ensure that the DNA blots were technically satisfactory. Most filters were simultaneously probed with 754 and pERT87.8. The filters were subsequently hybridised with the other probes.

Prehybridisation was carried out in $3 \times \mathrm{SSC}$, $0 \cdot 1 \%$ SDS, $2 \times$ Denhardt's, and $100 \mu \mathrm{g} / \mathrm{ml}$ denatured salmon sperm DNA at $65^{\circ} \mathrm{C}$. Hybridisation was performed in the same solution, with addition of the denatured radiolabelled probe. Filters were washed for 30 minutes each in $2 \times$ SSC, $0.1 \%$ SDS; $1 \times$ SSC, $0.1 \%$ SDS; and $0.2 \times \mathrm{SSC}, 0.1 \%$ SDS at $65^{\circ} \mathrm{C}$.

Autoradiography was at $-70^{\circ} \mathrm{C}$ with DuPont intensifying screens, exposing for one to six days. For reprobing, filters were stripped in $0.4 \mathrm{~mol} / \mathrm{l}$ $\mathrm{NaOH}$ for one hour at $42^{\circ} \mathrm{C}$, followed by a 30 minute wash in $0.2 \mathrm{~mol} / \mathrm{l}$ Tris- $\mathrm{Cl}(\mathrm{pH} 7.5), 0.5 \%$ SDS, and $0 \cdot 1 \times$ SSC.

\section{PROBE ORIGINS}

The pERT87 clones (DXS164) were derived from a library highly enriched for human DNA from Xp21, ${ }^{11}$ obtained using DNA from a male patient with a microscopically visible deletion. ${ }^{4}$ Three unique sequence subclones from the pERT87 region, pERT87.1, pERT87.8, and pERT87.15, covering $50 \mathrm{~kb}$, were used in this study. These sequences have previously been shown to detect deletions in some DMD patients. ${ }^{3}$

Probe $\mathrm{pXJ} 1 \cdot 1$ was derived from the DNA of a female patient with muscular dystrophy, who was found to have an $\mathrm{X}$; autosome translocation, $t(X ; 21)(p 21 ; p 12) .^{5}$ The autosomal breakpoint is within a region of ribosomal RNA genes. ${ }^{12}$ Using rRNA sequences as probes, the region spanning the breakpoint was cloned, and a unique sequence from the $\mathrm{X}$ chromosomal portion was isolated and shown to reveal deletions in some DMD patients. ${ }^{6}$

Probe 754 (DXS84) was selected from a flow sorted X chromosome library. ${ }^{10}$ It detects a Pst I polymorphism and has been localised to $\mathrm{Xp} 21 \rightarrow \mathrm{p} 11 \cdot 3$.

\section{Results}

The DNA of 156 DMD patients has been hybridised
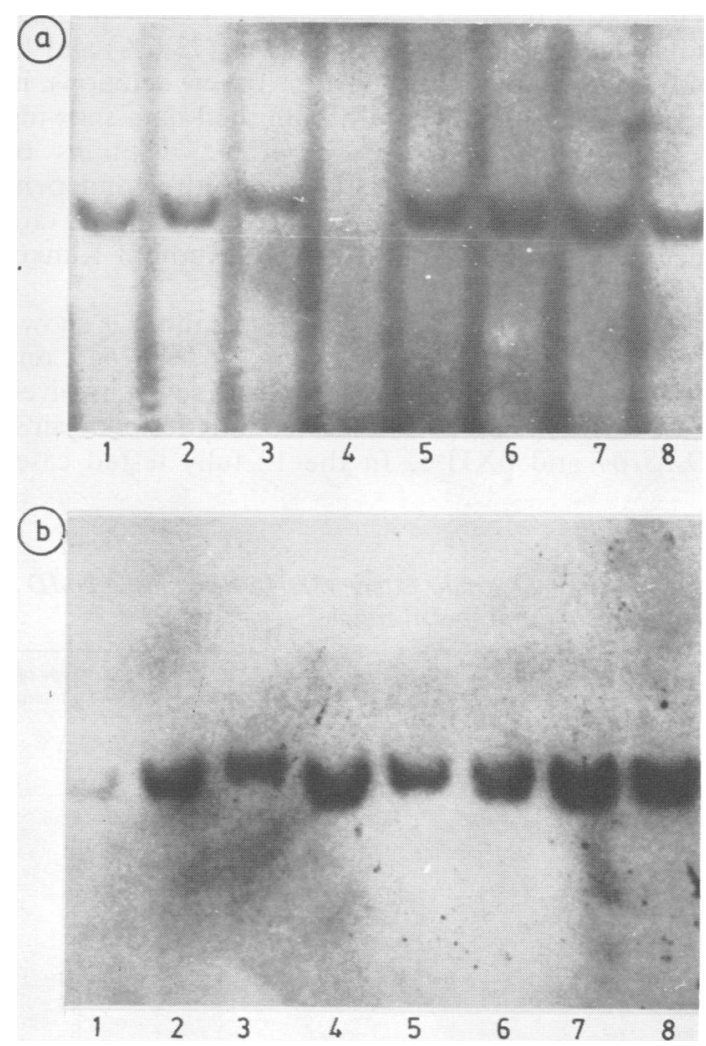

FIGURE (a) Autoradiogram of $10 \mu \mathrm{g}$ DNA from eight DMD cases digested with PstI, run out in $0.8 \%$ agarose, blotted onto a Zetaprobe filter, and probed with pERT87.1. The DNA in track 4 shows a deletion in DXS164 with this probe; all other tracks show the normal band. (b) Autoradiogram of the same filter, stripped and reprobed with $p X J 1 \cdot 1$. The DNA in all tracks, including track 4, shows the normal band and so is not deleted for this locus. 
with probes pERT87.1, pERT 87.8, pERT 87.15, and $\mathrm{pXJ} 1 \cdot 1$ to evaluate the frequency and extent of any DNA deletions present. The 156 patients studied represent 140 different kindreds and presumably, therefore, 140 separate mutational events.

The DNA of 16 cases is deleted for one or more of the probes used. The table shows a summary of the extent of each deletion in relation to the probes available. Two of the deletions represented in the table are in brothers, and the sample therefore contains 15 independent deletions, representing $10.7 \%$ of the kindreds studied. This is similar to the previously reported figure of $7 \cdot 2 \%$ for deletions of DNA in DMD patients using pERT87 probes. ${ }^{1}$

The 140 kindreds in our study consist of 118 sporadic cases and 22 families with more than one affected subject, a similar distribution to that reported from other large unselected clinic populations. Three of the 22 familial cases $(13.6 \%)$ and 12 of the 118 sporadic cases $(10 \cdot 2 \%)$ show deletions, in reasonable agreement with published data showing $8.3 \%$ familial and $5.8 \%$ sporadic deletions of DXS164. ${ }^{1}$ These data sets are not entirely independent, as some of the currently reported data are included in the collaborative publication of Kunkel et al. ${ }^{1}$

The extent of the 15 individual deletions is shown in the table. Six involved only DXS164, one involved only probe site $\mathrm{pXJ} 1 \cdot 1$, and seven involved both loci. One case could not be fully tested against DXS164 and pXJ1.1. In the 12 fully tested cases

TABLE Summary of the extent of DNA deletions in DMD in relation to the probes available.

\begin{tabular}{|c|c|c|c|c|c|c|}
\hline \multirow{3}{*}{$\begin{array}{l}\text { Case } \\
\text { No }\end{array}$} & \multicolumn{3}{|l|}{ DXS164 } & \multirow{3}{*}{$\begin{array}{l}\text { Not yet } \\
\text { allo- } \\
\text { cated } \\
\overline{p X J 1 \cdot I}\end{array}$} & \multirow{3}{*}{$\frac{\text { DXS84 }}{754}$} & \multirow{3}{*}{$\begin{array}{l}\text { Type of } \\
\text { mutation }\end{array}$} \\
\hline & $p E R T 87 \cdot 15$ & $p E R T 87 \cdot 8$ & $p E R T 87 \cdot 1$ & & & \\
\hline & & & & & & \\
\hline 18 & + & {$[-$} & -1 & + & + & F \\
\hline 70 & ND & - & ND & -1 & + & $\mathrm{S}$ \\
\hline $73^{*}$ & {$[-$} & - & - & $-]$ & + & $\mathbf{F}$ \\
\hline 88 & {$[-$} & - & $-]$ & + & + & $\mathrm{S}$ \\
\hline 163 & + & + & {$[-$} & $-]$ & + & S \\
\hline 250 & [- & - & - & -1 & + & $\mathrm{S}$ \\
\hline 414 & {$[-$} & - & $-]$ & + & + & $F$ \\
\hline 442 & + & + & + & {$[-]$} & + & S \\
\hline 466 & {$[-$} & - & - & -1 & + & $\mathrm{S}$ \\
\hline 467 & {$[-$} & - & - & -1 & + & $\mathrm{S}$ \\
\hline 567 & {$[-]$} & + & + & + & + & $\mathrm{S}$ \\
\hline 596 & {$[-$} & - & $-]$ & + & + & $\mathbf{S}$ \\
\hline 599 & + & + & {$[-]$} & + & + & $S$ \\
\hline $987^{*}$ & $1-$ & - & - & $-]$ & + & $\mathbf{F}$ \\
\hline 1026 & {$[-$} & - & - & $-j$ & + & $\mathbf{S}$ \\
\hline 1041 & {$[-$} & ND & ND & ND & ND & $\mathbf{S}$ \\
\hline
\end{tabular}

$+=$ normal homologous sequences to the probe are present in the patient's DNA.

$-=$ absence of homologous sequences to the probe in the patient's DNA. $\mathrm{ND}=$ not yet done. $\mathrm{F}=$ familial. $\mathrm{S}=$ sporadic.

*These two patients are brothers. where $D X S 164$ was involved in the deletions, eight were missing genomic sequences homologous to all pERT87 probes, one was deleted for sequences homologous to two probes (pERT87.1 and pERT87.8), and three were missing only one pERT site (pERT87.1 only, pERT87.15 only, and pERT 87.1 in combination with pXJ1.1 only). None of the DNA samples showed deletion of $D X S 84$.

\section{Discussion}

We have screened the DNA of 156 DMD patients, representing 140 kindreds, with four probes which have been reported as revealing DNA deletions in approximately $7 \%$ of DMD patients. ${ }^{136}$ Our study shows $10.7 \%$ of DMD patients to be deleted for one or more of these probe sites. Our data and those of others ${ }^{1}$ show a rate of deletion detection approximately 3\% higher, with the DNA probes used, in familial cases compared with sporadic or isolated cases. The numbers are small and this could be a chance observation. There is no obvious pattern to the extent of deletions defined in familial versus sporadic cases. It has been suggested that this difference may reflect different proportions of deletion mutants among mutations arising in male and female gametes. ${ }^{1}$ Sporadic cases will include a substantial proportion of families in which the mother is not a carrier. They will, therefore, overrepresent mutations arising in female meiosis, relative to families with a clear family history of DMD. On this basis, a higher frequency of deletions in familial than in sporadic cases would imply that deletions are less frequent in female than in male mutations.

Of 140 mutations screened, eight fail to hybridise with pXJ1·1, 11 with pERT87.1, 10 with pERT87.8, and 10 with pERT87.15. The extent of these 15 deletions, shown in the table, is compatible with the previously suggested order along the chromosome ${ }^{1}$ : telomere $\rightarrow$ pERT87.15 $\rightarrow$ pERT87 $\cdot 8 \rightarrow$ pERT $87 \cdot 1 \rightarrow$ pXJ1· $1 \rightarrow 754 \rightarrow$ centromere.

It has been suggested that a region of deletion common to many cases is located adjacent to pERT87.8. ${ }^{1}$ In our data, 10 patients (out of 14 deletion cases tested with this probe) involve this site. However, our data also show that pERT87.1 and pERT87.15 homologous sequences are deleted in 11 and 10 (out of 13 and 14, respectively) of our cases. Cases 599 and 567 are only deleted for pERT87.1 and pERT87.15, respectively, although the extent of these deletions just proximal and distal to pERT 87.8 is unknown. Case 442 is only deleted for the region defined by $\mathrm{pXJ} 1 \cdot 1$, the most centromeric portion of the region involved in these deletions, with DXS164 intact, insofar as these 
pERT87 probes can tell. There is not, therefore, a single region common to all deletions causing DMD.

The simplest interpretation is that more than one site within this region can mutate to cause DMD. Another possible explanation of the fact that apparently different deletion sites cause a single disease phenotype could be the presence in the population of inversions within Xp21. However, we have seen no cases of deletion maps inconsistent with the currently accepted order, which would be expected to result in some cases of deletion following inversion.

The $D X S 164$ and $\mathrm{pXJ} 1 \cdot 1$ region for which many patients are deleted in full is at least $300 \mathrm{~kb}$. The total size of the DMD locus is unknown. Cytologically visible differences between translocations causing $\mathrm{DMD}^{13}$ suggest either that the gene is at least $1000 \mathrm{~kb}$ long, or that it is a site of frequent chromosome rearrangement. This is compatible with the observation that the pERT87 sites, deleted in some DMD patients, nevertheless show up to $5 \%$ meiotic recombination with DMD. ${ }^{1}$ Since only a limited number of cases have been examined with a limited number of probes, it seems entirely probable that yet further sites which can mutate to give the DMD phenotype will be discovered. If deletions are equally common elsewhere in the gene, a substantial proportion of all DMD could, conceivably, be due to large deletions of this nature.

If these deletions have their origin in inaccurate pairing and unequal exchange at meiosis, one might also expect to find subjects with duplication of these loci. We have not observed any cases with unusually strong bands, although we have limited confidence in our ability to distinguish double from single gene dosage in this way. Irregular crossing over at meiosis could also, in principle, generate males heterozygous for these polymorphic sites. We have never observed this phenomenon nor has it been reported.

Comparing the frequency and size of deletions seen in DMD with other disorders, there are differences in both respects. Approximately 1 to $2 \%$ of haemophilia B patients sampled have been shown to carry deletions, varying in size from approximately $10 \mathrm{~kb}$ to whole gene deletions. ${ }^{14} 15$ Gitschier et al $^{16}$ reported finding two deletions, of $21.9 \mathrm{~kb}$ and $39 \mathrm{~kb}$, among 92 haemophilia A patients. Yang et $a l^{17}$ identified three deletions amongst 28 cases of Lesch-Nyhan disease, comparable with the $10 \%$ deletion rate for DMD.

Case 73 and case 987 are brothers and have apparently similar deletions. No other affected family members are known. Their mother is either a carrier of the deletion or bears a premutation from which the deletions have arisen at meiosis. She is apparently homozygous at three polymorphic sites within this region, increasing the likelihood that she is a deletion heterozygote.

As more probes become available from within Xp21, more accurate maps can be built up, which should help in defining putative regions to search for expressed sequences. The identification of these cases opens up the possibility of 'jumping' a deletion to a unique region at the other end and examining the surrounding region for its role in DMD. In this way, a large proportion of Xp21 can be analysed by relatively simple means. Ultimately, this will contribute to a fuller understanding of the structure and organisation of the regions of DNA in Xp21 involved in DMD.

We gratefully acknowledge the financial support of the Muscular Dystrophy Group of Great Britain and Northern Ireland and the Generation Trust Fund. In addition, we are indebted to Dr Lou Kunkel for releasing the pERT87 probes to us and to Professor P Pearson for 754. We also thank Elizabeth Manners for her essential organisational role in this project and unfailing help in the preparation and typing of this manuscript.

\section{References}

1 Kunkel LM, Hejtmancik JF, Caskey CT, et al. Analysis of deletions in DNA from patients with Becker and Duchenne muscular dystrophy. Nature 1986;322:73-7.

2 Moser H. Duchenne muscular dystrophy: pathogenetic aspects and genetic prevention. Hum Genet 1984;66:17-40.

3 Monaco AP, Bertelson CJ, Middlesworth W, et al. Detection of deletions spanning the Duchenne muscular dystrophy locus using a tightly linked DNA segment. Nature 1985;316:842-5.

4 Francke U, Ochs HD, de Martinville B, et al. Minor Xp21 chromosome deletion in a male associated with expression of Duchenne muscular dystrophy, chronic granulomatous disease, retinitis pigmentosa, and McLeod syndrome. Am J Hum Genet 1985;37:250-67.

5 Verellen-Dumoulin C, Freund M, deMeyer R, et al. Expression of an X-linked muscular dystrophy in a female due to translocation involving Xp21 and non-random inactivation of the normal X chromosome. Hum Genet 1984;67:115-9.

6 Ray PN, Belfall B, Duff C, et al. Cloning of the breakpoint of an $\mathrm{X} ; 21$ translocation associated with Duchenne muscular dystrophy. Nature 1985;318:672-5.

7 Southern EM. Detection of specific sequences among DNA fragments separated by gel electrophoresis. J Mol Biol 1975;98:503-17.

${ }^{8}$ Kunkel LM, Smith KD, Boyer SH, et al. Analysis of human Ychromosome-specific reiterated DNA in chromosome variants. Proc Natl Acad Sci USA 1977;74:1245-9.

9 Feinberg AP, Vogelstein B. A technique for radiolabeling DNA restriction endonuclease fragments to high specific activity. Anal Biochem 1983;132:6-13.

10 Hofker MH, Wapenaar MC, Goor N, Bakker E, van Ommen GJB, Pearson PL. Isolation of probes detecting restriction fragment length polymorphisms from $X$ chromosome-specific libraries: potential use for diagnosis of Duchenne muscular dystrophy. Hum Genet 1985;70:148-56. 
1 Kunkel LM, Monaco AP, Middlesworth W, Ochs HD, Latt SA. Specific cloning of DNA fragments absent from the DNA of a male patient with an $\mathrm{X}$ chromosome deletion. Proc Natl Acad Sci USA 1985;82:4778-82.

12 Worton RG, Duff C, Sylvester JE, Schmickel RD, Willard HF. Duchenne muscular dystrophy involving translocation of the dmd gene next to ribosomal RNA genes. Science 1984;224:1447-9.

13 Boyd Y, Buckle VJ. Cytogenetic heterogeneity of translocations associated with Duchenne muscular dystrophy. Clin Genet 1986;29:108-15.

14 Giannelli F, Choo KH, Rees DJG, Boyd Y, Rizza CR, Brownlee GG. Gene deletions in patients with haemophilia B and anti-factor IX antibodies. Nature 1983;303:181-2.
15 Chen SH, Yoshitake S, Chance PF, et al. An intragenic deletion of the factor IX gene in a family with haemophilia B. J Clin Invest 1985;76:2161-4.

${ }^{16}$ Gitschier J, Wood WI, Tuddenham EGD, et al. Detection and sequence of mutations in the factor VIII gene of haemophiliacs. Nature 1985;315:427-30.

17 Yang TP, Patel PI, Chinault AC, et al. Molecular evidence for new mutation at the hprt locus in Lesch-Nyhan patients. Nature $1984 ; 310: 412-4$.

Correspondence and requests for reprints to $\mathrm{Mr} \mathrm{K}$ Hart, Paediatric Research Unit, Guy's Hospital Medical School, Guy's Tower, London SE1 9RT. 